\section{Telangiectasia hemorrágica hereditária: uma nova abordagem cirúrgica}

\author{
Diego Rosado de Miranda ${ }^{1}$, Márcio Meira Lima ${ }^{2}$, \\ André Luiz Monteiro Cavalcante ${ }^{3}$, Elias Bezerra Leite ${ }^{4}$, \\ Sebastião Diógenes Pinheiro5, Marcos Rabelo de Freitas ${ }^{6}$
}

\section{Hereditary hemorrhagic telangiectasia- a new surgycal approach}

\section{INTRODUÇÃO}

A Telangiectasia Hemorrágica Hereditária (THH) ou doença de RenduOsler-Weber é uma anomalia vascular caracterizada por múltiplas dilatações de capilares e vênulas da pele e mucosas. E doença autossômica dominante, apresenta igual distribuição entre os sexos e sua incidência é de 1-2/100.000 habitantes. ${ }^{1}$

Pode ocorrer sangramento em diversos locais, mas epistaxe é o mais comum, presente em 90\% dos casos ${ }^{2}$. A lesão básica encontra-se na parede dos vasos, com defeitos nas camadas elástica e muscular que os torna mais propensos a sangramento ${ }^{1,3}$

Várias terapias têm sido utilizadas para controle das epistaxes, nenhuma inteiramente satisfatória ${ }^{4}$ As opções são tamponamentos nasais, cauterizações, hormonioterapia, embolizações vasculares, fascioplastia e septodermoplastia 5 . A Cirurgia de Young consiste na oclusão nasal, que impede o atrito do ar com as lesões telangiectásicas, evitando a epistaxe. ${ }^{6}$

\section{RELATO DE CASO}

A.B.L., 56 anos, história de epistaxe recorrente, principalmente à esquerda, desde os 15 anos de idade. Já havia sido submetido a várias transfusões sanguíneas, bem como cauterizações e fascioplastia com resultados insatisfatórios. $\mathrm{Na}$ admissão hospitalar apresentava-se emagrecido e hipocorado (+++/4+). Múltiplas lesões telangiectásicas eram vistas em lábio superior, ponta do nariz e fossas nasais. O hematócrito era de $24 \%$. O paciente foi então submetido à Cirurgia de Young no lado esquerdo, por este ser bem mais sintomático. Realizou-se uma incisão circular na junção cutâneo-mucosa (Figura 1) preservando as vibrissas no lado do vestíbulo com fechamento em dois planos, um mucoso mais interno e outro cutâneo mais externo. Após dois anos e três meses de acompanhamento não houve nenhum episódio de epistaxe e ocorreu normalização hematológica. Não houve distúrbio respiratório e o aspecto estético foi bastante satisfatório.

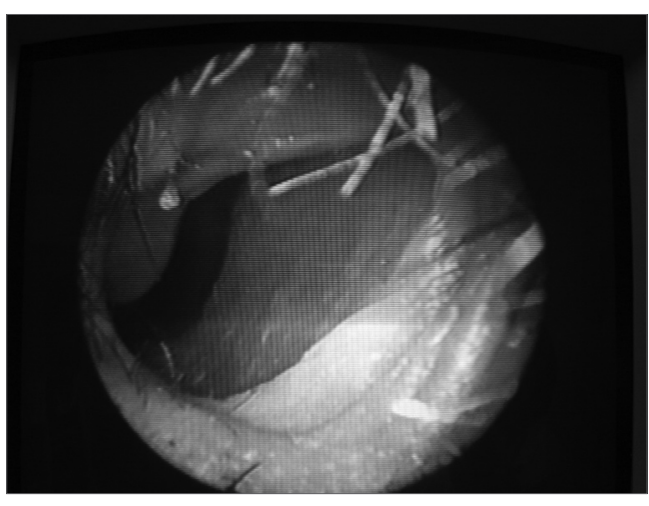

Figura 1. Junção cutâneo-mucosa da fossa nasal: local da incisão e do fechamento em dois planos na técnica de Young.

\section{DISCUSSÃO \\ A epistaxe de repetição é o sinto- ma mais comum da THH, presente em $90 \%$ dos casos ${ }^{2}$. Este era o único sintoma do nosso paciente. O quadro iniciou-se na segunda década de vida, tornando-se cada vez mais intenso, o que condiz com os dados da literatura. \\ A efetividade da técnica de Young no controle da epistaxe em pacientes com THH é atribuída à eliminação da turbulência aérea em uma mucosa friável e com vasos doentes ${ }^{6}$. Este procedimento é pouco relatado na literatura, mostran- do-se extremamente eficaz no controle}

da epistaxe recorrente. O nosso paciente não apresentou nenhum episódio de epistaxe após dois anos e quatro meses da cirurgia, o que é concordante com as informações encontradas na literatura.

\section{COMENTÁRIOS FINAIS}

A Cirurgia de Young demonstrou ser um tratamento eficaz para a epistaxe recorrente secundária à THH. Não foi observada nenhuma alteração respiratória e a oclusão nasal foi bem tolerada. Embora o número de pacientes submetidos a esta técnica seja ainda restrito, podemos afirmar que este procedimento pode ser incluído no arsenal terapêutico do otorrinolaringologista no sentido de tentar minimizar os sintomas destes pacientes trazendo uma melhor qualidade de vida.

\section{REFERÊNCIAS BIBLIOGRÁFICAS}

1.Pau H, Carney AS, Murty GE. Hereditary haemorrhagic telangiectasia (Osler-WeberRendu syndrome): otorhinolaryngological manifestations. Clin Otolaringol 2001;26:938.

2.Byahatti SV, Rebeiz EE, Shapshay SM. Hereditary Haemorrhagia Telangiectasia: What the otolaryngologist should know. Am J Rhinol 1997;11:55-62

3.Gluckman JL, Portugal LG. Modified Youngs procedure for refractory epistaxis due to hereditary hemorrhagic telangiectasia. Laringoscope 1994;104:1174-7.

4.Jahnke V. Ultrastructure of Hereditary Hemorrhagic Telangiectasia. Arch Otololaryngol 1970;91:262-5

5.Hashimoto K and Pritzker MS. Hereditary hemorrhagic telangiectasia.: An Eletron microscopic study. Oral surg 1972;34:751-7.

6.Young A. Closure of the Nostrils in Atrophic Rhinitis. J Laryngol Otol 1997, 81:515-524.

Graduação pela UFRN - 2000. Residente em ORL-UFC.

Graduação em Medicina pela UFC. Residente de ORL-UFC.

Residência em Otorrinolaringologia pela UFC, Médico assistente do Serviço de Otorrinolaringologia da Faculdade de Medicina da Universidade Federal do Ceará Residência em Otorrinolaringologia pela UFC. Médico assistente do Serviço de Otorrinolaringologia da Faculdade de Medicina da UFC.

${ }^{5}$ Doutor em Medicina pela Universidade de São Paulo. Professor Adjunto da Disciplina de Otorrinolaringologia da Faculdade de Medicina UFC. ${ }^{6}$ Mestre em Medicina pela USP/ Ribeirão Preto. Professor assistente da Disciplina de Otorrinolaringologia da Faculdade de Medicina da UFC. Universidade Federal do Ceará - Faculdade de Medicina - Hospital Universitário Walter Cantídio, Serviço de Otorrinolaringologia.

Endereço para correspondência: R. Prof. Costa Mendes 1608 Rodolfo Teófilo 60430-140 - Dep. de Cirurgia da Faculdade de Medicina da Universidade Federal do Ceará $3^{\circ}$ andar.

Este artigo foi submetido no SGP (Sistema de Gestão de Publicações) da RBORL em 27 de abril de 2005. cod. 273.

Artigo aceito em 1 de maio de 2006 